\title{
The Protective Effect of a Combination of Human Intracellular and Extracellular Antibodies against Highly Pathogenic Avian Influenza H5N1 Virus
}

XIAO ZHANG ( $\nabla$ zhangxiao@njmu.edu.cn )

Nanjing Medical University

Chen Lu

Nanjing Medical University

Xinyan Li

Nanjing Medical University

Yaxuan Di

Nanjing Medical University

Fangzhou Liu

Nanjing Medical University, Jiangsu Cancer Hospital

Zhenqing Feng

Nanjing Medical University

Research article

Keywords: Highly pathogenic avian influenza H5N1 virus, intracellular antibody, extracellular antibody, survival, cytokines, dynamics of viral replication

Posted Date: November 14th, 2019

DOl: https://doi.org/10.21203/rs.2.17311/v1

License: (c) (i) This work is licensed under a Creative Commons Attribution 4.0 International License.

Read Full License 


\section{Abstract}

Background:Highly pathogenic avian influenza H5N1 virus is a serious threat to humans. Due to its antiviral activity, antibody-based therapy is one of the possible effective countermeasures. Here,a combination of intracellular and extracellular human antibodies was investigated and showed a better protective effect. Methods: The scFv4F5-based intracellular antibody and full-length IgG1 extracellular antibody vectors were constructed or expressed, respectively. In vitro, the sensitivity, specificity and affinity of these antibodies were detected by western blotting, ELISA, flow cytometry, Biacore X100 SPR technique and microneutralization assay. In vivo, the protective effect of the combination of antibodies and the dynamics of viral replication were tested, and the related cytokines and proteins were detected by ELISA, western blotting and qPCR. Results: The intracellular antibody could inhibit H5N1 virus propagation in A549 cells in a dose-dependent manner. The protective effect of IgG1 was good in posttreatment therapy in a mouse model. When the intracellular antibody was pre-transfected in a combination regimen with $\lg \mathrm{G} 1$, it had a better protective effect than $\lg \mathrm{G} 1$ alone. The protective effect was primarily accomplished by inducing the secretion of cytokines, i.e., IFN-y, IL-6, and IL-10, and the expression of apoptosis-related proteins, i.e., Bim and cleaved PARP. Conclusions: This antibody combination technique could be used as an appropriate and powerful alternative to antiviral therapy.

\section{Background}

The H5N1 virus has spread from wild birds to domestic poultry and can potentially infect humans with either high mortality or morbidity $[1,2]$. The last century witnessed four human pandemics of influenza worldwide, each of which differed from the others in aetiology, epidemiology, and severity of the disease [3-6]. It is essential to develop effective therapies for human populations at risk for H5N1 virus infections as well as those subsequently infected by human-to-human transmissions [7, 8]. The viral surface glycoproteins HA and NA, which are highly susceptible to antigenic variations due to antigenic shift and drift, are the major targets of anti-influenza virus therapies [9-11].

In a previous study [12], we obtained a broadly neutralizing single chain variable fragment 4F5 (scFv4F5) antibody from a human vaccine immunized-phage-display library, which was shown to be effective against clade 2 and clade 9 H5N1 viruses. The scFv4F5 antibody can bind to HA protein and thus interfere with viral entry by steric hindrance. Furthermore, this antibody showed satisfactory protection against H5N1 influenza A virus in pre- and post-challenge studies in an embryonated chicken egg model.

Intracellular immunization [13] is a promising therapeutic technique that uses various forms of gene transfer to provide specific cellular resistance to viral infection. In addition to antisense oligonucleotides [14], ribozymes [15], and RNA interference [16], another approach for the inhibition of viral protein functions is by intracellularly expressed antibody, also known as intrabody [17]. A single chain variable fragment (scFv), which consists of the $\mathrm{VH}$ and $\mathrm{VL}$ regions of the variable antigen-binding site of an immunoglobulin, is connected with a short linker sequence. ScFv is the smallest functional unit of 
parental antibody. Intrabodies have much higher specificity against target proteins than oligonucleotides, ribozymes, or RNA interference molecules.

When scFv is used as an intrabody, it has several advantages over immunoglobulins: a simple and compact structure, higher stability and solubility, and low immunogenicity. However, scFv antibodies often have some shortcomings, such as low affinity, single function, poor stability and rapid elimination in vivo, which restrict their wide application. Compared to scFv antibodies, whole molecule $\lg G$ antibodies have antibody-dependent cellular cytotoxicity (ADCC) and CDC (complement-dependent cytotoxicity) functions due to their Fc fragment, which easily recognizes Fcy receptors (FcyRs) on immune cells upon binding to tumour or viral antigens. However, whole molecule IgG have failed to be transduced into cells.

Each approach has advantages for therapeutic application. In this study, the scFv4F5 gene was cloned into a eukaryotic expression vector and pre-transfected to be expressed as an intracellular antibody, which improves its antiviral effect in cells. Moreover, the scFv4F5 molecule was remodelled to a fulllength IgG1 as an extracellular antibody, which enhanced its ADCC and CDC effects on virus infection outside the cells. The combination antibody treatment had a better protective effect when used in challenge studies of mouse models.

\section{Results}

\section{The eukaryotic expression vector pCAG-scFv4F5-GFP was constructed and then transfected into A549 cells, and the expressed intracellular antibody could inhibit H5N1 virus propagation.}

The scFv4F5 antibody gene with a His-HA-tag sequence of $~ 850$ bp was amplified from the pComb3XSSscFv4F5 plasmid. The PCR product was successfully inserted into the pCAG-GFP plasmid. As shown in Fig. 1, the pCAG-scFv4F5-GFP plasmid containing the scFv4F5 gene was approximately $1600 \mathrm{bp}$, while the blank plasmid pCAG-GFP containing GFP was 750 bp (Fig. 1A). This was further corroborated by the sequence analysis. When the recombinant plasmid pCAG-scFv4F5-GFP was transfected into A549 cells mixed with the liposome Lipofectamine 2000 at a ratio of 1:3, the number of GFP-positive cells was detected by fluorescence microscopy (Fig. 1B) and was up to 72\% (Fig. 1C) as detected by flow cytometry 48 hours later. In addition, the expression of intracellular antibody scFv4F5 was detected by western blotting at 24, 48 and 72 hours, as shown in Fig. 1D, and the $55 \mathrm{kD}$ fragment of the scFv4F5 and GFP fusion protein could be detected in all transfected cells, and had the highest production at 48 hours after transfection. These results indicated that the antibody was expressed correctly with this eukaryotic expression system.

Furthermore, the relative H5N1 virus quantity was detected in A549 cells, which were pre-transfected with scFv4F5 vectors and then infected with H5N1. Decreasing virus quantity was detected with the increasing dose of pCAG-scFv4F5-GFP transfected from 1 to $5 \mu \mathrm{g}$ (Fig. 2A). The percentage of H5N1 virus-positive cells ranged from $95.2 \%$ to $30.4 \%$ (Fig. $2 \mathrm{~B}$ ). This indicated that the intracellular antibody could inhibit the propagation of H5N1 virus in a dose-dependent manner. 


\section{Full-length human anti-H5N1 virus IgG1 antibody-expressing vectors were constructed and then stably transfected into CHO-DG44 cells.}

The IgG1 genes $\mathrm{VH}, \mathrm{CH} 1, \mathrm{CH} 2-3, \mathrm{~V} \lambda$, and $\mathrm{C} \lambda$ were amplified from different plasmids, and whole $\mathrm{H}$ and $\lambda$ chain genes were amplified by overlapping PCR and inserted into the mammalian expression pCl-neo vector. As shown in Fig. $3 \mathrm{~A}, \mathrm{~V} \lambda, \mathrm{C} \lambda, \mathrm{VH}$, and $\mathrm{CH} 1$ were $\sim 350 \mathrm{bp}$, the $\lambda$ and $\mathrm{CH} 2-3$ gene fragments were $750 \mathrm{bp}$, while the whole $\mathrm{H}$ gene was $\sim 1500 \mathrm{bp}$. All the gene fragment sizes were as expected. The stable cell line CHO-DG44, which can express IgG1 antibody, was screened with $500 \mu \mathrm{g} / \mathrm{ml} \mathrm{G} 418$, and a large amount of cells that were not successfully transfected with $\mathrm{pCl}-\lambda$ and $\mathrm{pCl}-\mathrm{H}$ plasmids died 2 days later. Clone formation was visible by 5-10 days (Fig. 3B). The expression of whole molecular IgG1 antibody protein was detected by western blot. As shown in Fig. 3C, a $25 \mathrm{kD} \lambda$ chain and a $55 \mathrm{kD} H$ chain were detected in both the supernatant and cell pellet. The collected supernatant was purified using a protein $\mathrm{G}$ affinity column and detected by SDS-PAGE. The $25 \mathrm{kD}$ and $55 \mathrm{kD}$ bands can be observed clearly in Fig. $3 \mathrm{D}$. The protein had a high purity and high production, with $5 \mathrm{mg}$ recombinant protein obtained from 100 $\mathrm{ml}$ supernatant, which was sufficient for therapeutic assays in vivo.

\section{The purified full-length human IgG1 antibody has high specificity, sensitivity and affinity against H5N1 virus}

The function of IgG1 was determined by ELISA, flow cytometry, Biacore SPR biosensor technique, and microneutralization assay, and the assays measured the following four parameters. i) The binding reactivity and sensitivity of whole molecule IgG1 and ScFv4F5 protein were detected using H5N1 virus as antigen. In Fig. $4 \mathrm{~A}$, the $\mathrm{OD}_{450}$ values of full-length $\lg \mathrm{G} 1$ and scFv4F5 were almost the same at the same concentrations with no statistically significant differences, which illustrated that the binding reactivity of the IgG1 antibody was similar to that of scFv4F5. ii) The specificity of the IgG1 antibody was also detected by flow cytometry. IgG1 could bind up to $95 \%$ of virus-infected cells, compared to $0.1 \%$ for a commercial human IgG1 antibody (Fig. 4B), which demonstrated that IgG1 had a specific binding reactivity against $\mathrm{H} 5 \mathrm{~N} 1$ virus. iii) The affinities of IgG1 and scFv4F5 to the H5N1 virus glycoprotein rHA1 were measured and were expressed as the dissociation constant (Kd value). The Kd of IgG1 was 4.47×1012 , while that of scFv4F5 was $9.74 \times 10^{-9}$ (Fig. 4C), indicating that IgG1 had a better advantage against the virus than scFv4F5. iv) Finally, a microneutralization assay was used to detect the $\mathrm{IC}_{50}$ of the antibodies. The IC $\mathrm{IC}_{50}$ of IgG1 was $0.01521 \mu \mathrm{g} / \mathrm{ml}$, which was lower than $0.3451 \mu \mathrm{g} / \mathrm{ml}$ of scFv4F5. Fig. 4D shows the inhibitory effect of the antibodies against H5N1 virus proliferation in MDCK cells. All these results indicated that the remodelled IgG1 antibody had a high specificity, sensitivity and affinity. 


\section{A combination of the intracellular and extracellular antibodies has a better protective effect in a mouse model challenged with H5N1 virus}

In vivo, when mice infected with $100 \mathrm{TCID}_{50} \mathrm{H} 5 \mathrm{~N} 1$ virus were treated with $\mathrm{IgG} 1 \mathrm{from} 2 \mathrm{mg} / \mathrm{kg}$ to 15 $\mathrm{mg} / \mathrm{kg}$, the survival increased with increasing IgG1 concentration. Fourteen days later, the mice in the control group that were injected with PBS and the $2 \mathrm{mg} / \mathrm{kg}$ group all died. Mouse survival was at $16.67 \%$, $66.67 \%$, and $100 \%$ when $\mathrm{lgG} 1$ was $5 \mathrm{mg} / \mathrm{kg}, 10 \mathrm{mg} / \mathrm{kg}, 15 \mathrm{mg} / \mathrm{kg}$, respectively. Survival was up to $100 \%$ at the $15 \mathrm{mg} / \mathrm{kg}$ dose (Fig. 5A). The protective effect of IgG1 against the virus was dose dependent. In addition, scFv4F5 $(15 \mathrm{mg} / \mathrm{kg})$ was also used as a parallel control, and the survival of the mice was at $66.67 \%$.

Next, the antibody combination was used, with IgG1 administered at $15 \mathrm{mg} / \mathrm{kg}$ invariantly and the pCAGscFv4F5-GFP vector at $0 \mu \mathrm{g}, 5 \mu \mathrm{g}, 10 \mu \mathrm{g}, 20 \mu \mathrm{g}$, or $30 \mu \mathrm{g}$. The protective effect against $500 \mathrm{TCID}_{50} \mathrm{H} 5 \mathrm{~N} 1$ virus increased with increasing scFv4F5 expression vector dose. The survival rates were $10.67 \%, 16.67 \%$, $33.33 \%, 50.00 \%$, and $66.67 \%$, respectively. When the dose of pCAG-scFv4F5-GFP plasmid continually increased to $50 \mu \mathrm{g}$, the protective effect was not gradually improved (Fig. 5B).

\section{Increased levels of IFN-y, CD8+ T cells, and related cytokines play an important role in the antiviral protection induced by the antibody combination.}

Serum and PBMCs were collected from the $15 \mathrm{mg} / \mathrm{kg}$ IgG1- and $30 \mu \mathrm{g}$ pCAG-scFv4F5-GFP plasmidtreated groups, and 3 mice of each were detected. First, levels of cytokines, i.e., IFN- $a$, IFN- $\beta$, IFN- $\gamma$, IL- 6 and IL-10, were detected by ELISA. Fig. $6 \mathrm{~A}$ shows that IFN- $\alpha$ and IFN- $\beta$ levels were not significantly different at any time. IFN-y, IL-6 and IL-10 levels first increased on the $2^{\text {nd }}$ day and then decreased after reaching their maximum on the $8^{\text {th }}$ day. This indicated that the antibody combination could significantly affect the secretion of the cytokines IFN-y, IL-6 and IL-10. Real-time PCR, which tested the expression of the corresponding genes, corroborated this result. Fig. 6B shows that IFN- $\alpha$ and IFN- $\beta$ expression levels were not significantly different at any time. IFN- $y$ expression first increased on the $2^{\text {nd }}$ day and then decreased after reaching its maximum on the $4^{\text {th }}$ day. IL- 6 and IL-10 expression first increased on the $4^{\text {th }}$ day and then decreased after reaching their maximum on the $8^{\text {th }}$ day.

The apoptosis-related proteins Bim and cleaved PARP were detected by western blot. As Fig. 6C shows, the protein expression of Bim remained at a comparably high level on the $12^{\text {th }}$ and $14^{\text {th }}$ day after infection, while the expression of cleaved PARP reached its maximum on the $4^{\text {th }}$ day, but showed no significant increase 8 days later. These results may indicate that the antibody combination can induce cell apoptosis.

The dynamics of viral replication were also determined. Virus titers (PFU/ml) were determined by a plaque-forming assay on MDCK cells as previously described [18]. As shown in Fig. 6D, 24 hours after 
antibody injection, virus replication reached the highest at $10^{8}$. Viral titers decreased after repeated administration, falling to $10^{2} 14$ days later, which revealed that the antibody combination exerted a positive effect on inhibiting viral replication.

\section{Discussion}

Antibody-based therapeutics have gained significant interest in recent years. An increasing number of antibody drugs that target viruses or carcinoma cells have been successful in the treatment of diseases. There are different structures of antibodies from various sources that have been developed for anti-H5N1 virus therapies, with the viral surface HA and NA as the major targets [19-22]. In the present paper, the protective effect of a combination of intracellular and extracellular antibodies against human influenza virus H5N1 was investigated. This is the first report of combination antibody-mediated inhibition of H5N1 virus propagation and secretion.

The cytoplasm is an important environment for virus replication and amplification. However, most of the full-length IgG and some of the Fab or ScFv antibodies have been limited to use because they cannot penetrate the cells. These antibodies failed to enter the cells and to show inhibitory activities inside cells. Recently, some cell-penetrating antibodies that can internalize into cells have been developed by conjugation with a peptide [23]. Compared to the other intracellular therapies, i.e., antisense oligonucleotides, RNAi, shRNA, and siRNA, intracellular immunization based on scFvs is worthy of investigation for its several advantages, such as high specificity and long half-lives. Kaku et al. developed scFv-based intrabodies against RABV phosphoprotein (RABV-P), and when the scFv was transiently expressed in mouse neuronal cell lines before RABV infection, it severely inhibited the propagation and secretion of virus and the spread of infection [24]. In addition, intrabody scFvs possess several advantages over full-length IgG: a simple and compact structure, higher stability, and increased solubility. Intrabodies based on scFvs have already been developed against human immunodeficiency virus-1 [25], hepatitis $B$ virus [26], hepatitis $C$ virus [27], rotavirus [28], herpes virus [28, 29] and influenza virus [30]. The intrabody-based strategy can be applied to the development of future therapeutic agents against viruses because the cytoplasm is one of the most important environments for viral replication and amplification.

This study used scFv4F5, which was screened from vaccine-immunized human scFv libraries and could neutralize different clades of $\mathrm{H} 5 \mathrm{~N} 1$ viruses and bind to a conserved peptide in the haemagglutinin protein. The pre-expressed intrabody, which was pre-transfected as a scFv4F5 expression vector, had a significant effect on eradicating H5N1 viral propagation in H5N1 virus-infected A549 cells. This indicates that ScFv4F5 could be a prospective candidate for an intrabody; however, this inhibition might have been achieved partially due to an unexpectedly higher transfection efficiency compared to other expression systems. As such, the establishment of an appropriate delivery or application system is very important for further studies.

Furthermore, the Fc segment, which is the binding site on human IgG1 for FcyRI, FcyRII, RIII, C1q and FCRn, determines the effector function of the antibody, including ADCC and CDC. To maintain all of these 
advantages, scFv4F5 was converted into a full-length IgG molecule for use as an extracellular antibody. Our results showed that the IgG1 molecule affinity and $\mathrm{IC}_{50}$ were obviously better than those of scFv4F5. This was corroborated by the fact that IgG1 could inhibit H5N1 virus propagation and reduce the replication of the virus in mouse challenge models.

In conclusion, we demonstrated that scFv4F5, when pre-expressed as an intrabody in A549 cells, substantially inhibited the propagation of H5N1 virus. In addition, full-length human IgG1 was constructed and expressed and used as a combination with the intrabody in challenge studies in mouse models, which is one of the best animal models to study drug effects on H5N1 virus. The antibody combination could obviously improve the survival of the mice. This scFv-based intracellular immunization could be a candidate for a future therapeutic tool against H5N1 virus infection if combined with an appropriate delivery and application system, such as a viral vector. On the other hand, due to the animal model has its advantages and disadvantages, it maybe a rough ride for its using in clinical, at least we provide a powerful tool for the establishment of novel therapeutic agents against H5N1 virus infection.

\section{Conclusions}

Highly pathogenic avian influenza H5N1 virus is a serious threat to humans. Due to its antiviral activity, antibody-based therapeutics have gained significant interest in recent years. In the present paper, the protective effect of a combination of intracellular and extracellular antibodies against human influenza virus H5N1 was investigated. The scFv4F5-based intracellular antibody and full-length IgG1 extracellular antibody vectors were constructed or expressed, respectively. The intracellular antibody could inhibit H5N1 virus propagation in A549 cells in a dose-dependent manner. The protective effect of IgG1 was good in post-treatment therapy in a mouse model. When the intracellular antibody was pre-transfected in a combination regimen with $\lg G 1$, it had a better protective effect than $\lg \mathrm{G} 1$ alone. The protective effect was primarily accomplished by inducing the secretion of cytokines, and the expression of apoptosisrelated proteins. Our results support the antibody combination technique could be used as an appropriate and powerful alternative to antiviral therapy.

\section{Methods}

\section{Virus, Animals, chemical reagents and antibodies}

The viruses A/Jiangsu/1/2007 (H5N1) (GenBank: EU434686.1) was separated from a patient as described previously [7] and propagated in embryonated chicken eggs. The recombinant scFv4F5 plasmid containing the antibody $\mathrm{VH}$ and $\mathrm{V} \lambda$ chain sequence against the $\mathrm{H} 5 \mathrm{~N} 1$ virus were screened from phage display antibody library, scFv4F5 and rHA1 protein were prepared as previously [12]. The specific pathogen free (SPF) normal male BALB/ c weighing (20 \pm 2$) \mathrm{g}$, aged 6 weeks, were purchased from the Experimental Animal Center of the Nanjing Medical University. The plasmid pCAG-GFP was purchased from Addgene (plasmid \#11150, Cambridge, MA, USA) [31]. The pCl-neo mammalian expression vector 
was purchased from Promega Corporation (plasmid \#E1841, Madison, USA, 2009) [32]. pComb3XLambda (pubmed genebnk AF268281) and plgG was as a gift from Carlos F Barbas [33]. Antimouse cleaved PARP (\#94885) (1:1000) anti-mouse Bim (\#2933), anti-mouse ß-actin (\#4970) (1:2000) were purchased from Cell Signaling Technology (Danvers, MA, USA). Mouse anti influenza A virus nucleoprotein (NP) monoclonal antibody (\#MAB3325) was from Abnova Corporation (Taipei, Taiwan). RPE-conjugated AffiniPureF(ab') ${ }_{2}$ Fragment Goat Anti-mouse lgG (115-116-071) (1:2000), R-PE-conjugated AffiniPure $F\left(a b^{\prime}\right) 2$ Fragment Goat Anti-Human IgG (109-116-170) (1:2000) and Peroxidase AffiniPure Goat Anti-Mouse IgG (H+L) (115-035-003) (1:5000) were purchased from Jackson ImmunoResearch Inc (West Grove, PA, USA). HRP conjugated anti-His( \#A00612) (1:5000) was purchased from GenScript, Piscataway, NJ, CN), HiTrap Protein G affinity column (\#170404) and Ficoll-Paque (\#171440) were purchased from GE Healthcare (Piscataway, NJ囚USA). The restriction enzyme EcoR I (\#1040) and Sma I (\#1085) were purchased from Takara Biolnc (Otsu, Shiga, Japan). LipofectamineTM2000 was purchased from Thermo Fisher Scientific Search (San Jose, CA, USA). ELISA kits for IFN-a (\#42102), IFN- $\beta$ (\#42400), IFN-Y (\#MIF00), IL-6 (\#M6000B) and IL-10 (\#M1000B) were purchased from R\&D Systems Inc (Minneapolis, MN, USA).

\section{Cell culture}

The human lung carcinoma A549 cell was obtained from ATCC (\#CRM-CCL-185) (Manassas, VA, USA), Madin-Darby canine kidney (MDCK) cell and Chinese Hamster Ovary Cell CHO-DG44(DHFR-/-) $\varangle$ which were originally acquired from ATCC, was kindly provided by Dr. Jiao, CDC Jiangsu, China. A549 and MDCK cells were cultured in Dulbecco's Modified Eagle's Medium (DMEM) supplemented with $10 \%$ fetal calf serum (FCS; Atlanta Biologicals, Flowery Branch, GA, USA). CHO-DG44(DHFR-/-) was cultured in CHO DG44 Cells Media (Thermo Fisher Scientific, US). All cell lines were grown at $37^{\circ} \mathrm{C}, 5 \% \mathrm{CO} 2$.

\section{Construction, transfection of pCAG-scFv4F5-GFP vector, and confirmation of intracellular antibody expression}

The phagemid vector pComb3XSS-scFv4F5 was isolated and the scFv4F5 gene was amplified by PCR with the primers (5'- GGAATTCATGGA GCTGGTGCTGACCCAG-3') and (5'-

CCCCGGGAGCTTGCATAGTCGGGCAC GT-3'). Meanwhile, the restriction enzyme cloning site sequences EcoR I and Sma I were added to both sides of the fragment. After double enzyme digestion, the scFv4F5 gene was inserted to eukaryotic expression plasmid pCAG-GFP. The recombinant plasmid of the pCAGscFv4F5-GFP was constructed and detected with PCR and sequence analysis. For intrabody expression, recombinant plasmid pCAG -scFv4F5-GFP were transfected to human alveolar epithelial A549 cells mixed with liposome LipofectamineTM2000 at different ratio. The green fluorescent protein (GFP) was observed with fluorescence microscopy and detected by flow cytometry at different times. Furthermore, the 
transfected A549 cells were collected and the expression of antibody scFv4F5 was detected by western blot after lysed in RIPA buffer.

\section{Measurement of the inhibition of H5N1virus propagation by the intracellular antibody}

pCAG-ScFv4F5-GFP was transfected into A549 cells as above. After 24 hours, the cells were infected with $\mathrm{H} 5 \mathrm{~N} 1$ virus. The inhibition of H5N1 virus propagation by the intrabody was measured as the relative number of virus by flow cytometer at 48 hours after infection. The treated cells were detected by immunofluorescence microscope and analyzed by flow cytometer.

\section{Remodeling of scFv4F5 to full-length IgG1, expression and purification of extracellular antibody}

The variable region $\mathrm{V} \lambda$ and $\mathrm{VH}$ of scFv4F5 were amplified from pComb3XSS -scFv4F5, and constant region $\mathrm{C} \lambda, \mathrm{CH} 1$ were amplified from $\mathrm{pComb3X}$ Lambda.

$\mathrm{CH}_{2-3}$ was amplified from plgG vector, the primers used were as follow and restriction enzyme cloning site sequences EcoR I and Sma I, signal peptides were added. VH:(5'-

GGAATTCATGTCTGCACTTCTGATCCTAGCTCTTGTTGGAGC

TGCAGTTGCTATGGAGCTGGTGCTGACCCAG-3') and (5'-GACCAGGCAGCC

CAGGGCCGCGCTGGACCTGCTGCTTCCCCC-3'). CH1: (5'-GGGGGAAGCAG

CAGGTCCAGCGCGGCCCTGGGCTGCCTGGTC-3') and (5'-TTTGTCACAAG

ATTTGGGCTCACAAGATTTGGGCTCTGCTTT-3'). CH2-3: (5'-AAAGCAGAG

CCCAAATCTTGTGAGCCCAAATCTTGTGACAAA-3') and (5'-CCCCGGGTC AATGGTGGTGATGATGGTG-3').

V $\lambda$ : (5'-GGAATTCATGTCTGCACTTCTGAT

CCTAGCTCTTGTTGGAGCTGCAGTTGCTGAGGTGCAACTGGTGCAATCC-3') and (5'-

GTTACTCTGTTGCAGTAATAACACGCTGGGGCCCT TAGTGCT-3'). C $\lambda$ : (5'-

AGCACTAAGGGCCCCAGCGTGTTATTACTGCAACAGAGTAAC-3') and (5'-CCCCGGGTTATGAACATTCTG

TAGGGGC-3').

The full-length whole $\mathrm{H}$ and $\lambda$ chain genes were amplified by overlapping PCR and inserted to mammalian expression $\mathrm{pCl}$-neo vector, respectively. The recombinant $\mathrm{pCl}-\mathrm{neo}-\lambda$ and $\mathrm{pCl}$-neo-H plasmid were cotransfected to CHO-DG44(DHFR-/-) cells with LipofectamineTM2000. The positive cell line which can express antibody was screened with G418 and positive clones were subcloned for 3 times in order to obtain the stable cell line, which is expressing IgG1. The supernatant of the medium and cell lysed buffer were purified using protein $\mathrm{G}$ affinity column and detected by SDS-PAGE. The sensitivity, specificity and affinity of the whole molecular IgG1 antibody were detected by ELISA, flow cytometry and Biacore SPR biosensor technology. 


\section{Microneutralization assay}

Neutralizing antibody titers were determined by microneutralization assays performed on MDCK cells, following a previously described procedure. The $50 \%$ tissue culture infective dose $\left(\operatorname{TCID}_{50}\right)$ was calculated by the Reed and Muench method [34,35]. Briefly, serially diluted scFv or IgG antibodies were incubated with $100 \mathrm{TCID}_{50}$ of virus before added to the MDCK cells. Plates were incubated for $40 \mathrm{~h}$ before fixation of the cells with $4 \%$ paraformaldehyde. The presence of virus was detected with mouse anti influenza A virus NP antibody and Peroxidase AffiniPure Goat Anti-Mouse IgG. $\mathrm{OD}_{450}$ was valued and $\mathrm{TCID}_{50}$ was calculated. PBS were used as negative controls.

\section{Therapeutic effect of mice infected with H5N1 virus by the Intracellular and extracellular antibodies combination.}

Groups of 6-week-old Balb/c mice were used in all experiments and the study was approved by the ethics committee of Nanjing Mediacl University. The mice were randomly divided into 5 groups, each one with 6 mice. First, 100 TCID50 H5N1 viral suspensions were inoculated by intranasal administration,1 day later, the treated groups were administered with different concentration IgG1 antibody, 2mg/kg, $5 \mathrm{mg} / \mathrm{kg}$, $10 \mathrm{mg} / \mathrm{kg}, 15 \mathrm{mg} / \mathrm{kg}$, by intraperitoneal injection. Meanwhile, control group was only administered with the same volume of PBS at the same site. The survival of mice was observed and recorded every day for 14 days and Kaplan-Meier survival curves were constructed.

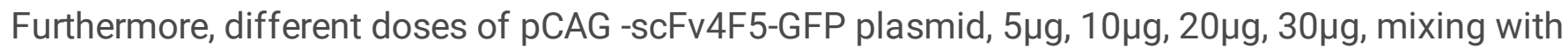
LipofectamineTM2000 were delivered by intramuscular injection to another 5 groups, each one with 6 mice, respectively. Meanwhile, control groups were only administered with the same volume of PBS at the same site. Two days later, $500 \mathrm{TCID}_{50} \mathrm{H} 5 \mathrm{~N} 1$ viral suspensions were inoculated by intranasal administration. The treated groups were administered with $15 \mathrm{mg} / \mathrm{kg} \mathrm{IgG} 1$ by intraperitoneal injection at 12,24 and 48 hours later. The survival of mice was observed and recorded every day for 14 days and Kaplan-Meier survival curves were constructed.

The coagulated blood and anticoagulated blood were collected at $0,2,4,8,12,14$ days, respectively. The serum was separated from coagulated blood for ELISA and the peripheral blood mononuclear cell (PBMC) were isolated from anticoagulated blood by Ficoll separation for real-time PCR. All the mice were sacrificed with $\mathrm{CO} 2$ euthanasia and the lung tissues were collected when the experiments finished. Briefly, the animals were put in the container and $100 \% \mathrm{CO} 2$ were injected with a flow rate of $30 \% \mathrm{CO} 2$ per minute of the chamber volume. 


\section{SDS-PAGE and Western blotting}

Treated tissues were collected and lysed in RIPA lysis buffer containing 1/50 of a protease inhibitor cocktail (Calbiochem, San Diego, CA, USA). The supernatants of the lysed proteins were suspended in loading buffer and separated by SDS-PAGE. The proteins were transferred onto PVDF membranes and blocked for $1 \mathrm{~h}$ at room temperature with $5 \%$ skim milk in PBS. To detect the expression of related proteins, add the specific diluted primary antibody and incubate $2 \mathrm{~h}$ at room temperature. Following with PBST washing, an HRP-conjugated secondary antibody was added and incubated for $1 \mathrm{~h}$ at room temperature. After PBST washing, the membranes were observed with ECL Detection solution (GE Healthcare).

\section{ELISA}

For the binding activity, H5N1 virus was coated onto ELISA plates. ScFv4F5 or IgG1 was then incubated with the coated wells for $2 \mathrm{~h}$ at $37^{\circ} \mathrm{C}$, washed 3 times with PBST and the second antibody HRP conjugated anti-His was added $1 \mathrm{~h}$ later at $37{ }^{\circ} \mathrm{C}$, washed 5 times with PBST. The TMB solution was added and developed in the dark for $10 \mathrm{~min}$. The enzymatic reaction was stopped by adding $2 \mathrm{M} \mathrm{H}_{2} \mathrm{SO}_{4}$ and enzymatic reaction $\mathrm{OD}_{450}$ values were read using a micro plate spectrophotometer.

\section{Real time qRT-PCR}

Total RNA from all PBMC samples was isolated using TRIzol and $1 \mu \mathrm{g}$ total RNA was reverse transcribed using M-MLV reverse transcriptase purchased from Life Technologies (Carlsbad, CA, USA), according to the manufacturer's instructions. All samples within each experiment were reverse transcribed at the same time. qRT-PCR using cDNA as a template with SYBR green detection was performed using a LightCycler96 system with FastStart SYBR Green Master Mix purchased from Roche. Appropriate no-RT and non-template controls were included in each 96-well PCR reaction, and dissociation analysis was performed at the end of each run to confirm the specificity of the reaction. Each gene expression level was normalized to mRNA levels of the housekeeping gene GAPDH. Fold changes of each gene's expression were compared to that of the untreated sample using the 2- $\Delta \Delta \mathrm{CT}$ method.

\section{Data analysis}

All the data analyses were performed using Prism 7 (GraphPad, San Diego, CA, USA).

\section{List Of Abbreviations}


ScFv: Single chain variable fragment, $\mathrm{VH}$ : Variable region of heavy chain, $\mathrm{CH} 1$ : Constant region 1 of heavy chain, $\mathrm{CH} 2-3$ : Constant region 2 and 3 of heavy chain, $\mathrm{V} \lambda$ : Variable region of light $(\lambda)$ chain, $\mathrm{C} \lambda$ : Constant region of light $(\lambda)$ chain, ADCC: Antibody-dependent cellular cytotoxicity, CDC: Complement-dependent cytotoxicity, PBMC: Peripheral blood mononuclear cell, FcyR: Recognizes Fcy receptors.

\section{Declarations}

\section{Ethics approval and consent to participate}

Not applicable

\section{Consent for publication}

Not applicable

\section{Availability of data and material}

The datasets used and/or analyzed during the current study are available from the corresponding author on reasonable request.

\section{Competing interests}

The authors declare that they have no competing interests

\section{Funding}

This work was supported by the National Natural Science Foundation of China (81202370 XZ, 81872426 XZ) and Natural Science Foundation of Jiangsu Province, China (BK20181372 XZ). The funders had no role in study design, data collection and analysis, decision to publish, or preparation of the manuscript.

\section{Authors' contributions}

Conceptualization, XZ and ZF; Methodology, XZ, CL, XL and YD; Software, XZ, and CL; Validation, XZ, FL, and ZF; Investigation, CL, XL and YD; Resources, XZ; Data curation, $X Z$ and FL; Writing - Original Draft Preparation, CL and XL; Writing - Review \& Editing, XZ and ZF; Visualization, XZ, CL, XL; Supervision, FL, 
ZF; Project Administration, ZF; Funding Acquisition, XZ. All authors have read and approved the manuscript.

\section{Acknowledgments}

We thank Dr. Jiao, Ministry of Health and Institute of Pathogenic Microbiology, Jiangsu Provincial Center for Disease Prevention and Control, China, who spent the countless hours helping us conduct this study.

\section{References}

1. Andrade CR, Ibiapina Cda C, Champs NS, Toledo Junior AC, Picinin IF. Avian influenza: the threat of the 21st century. J Bras Pneumol. 2009;35(5):470-479.

2. Kilbourne ED. Influenza pandemics of the 20th century. Emerg Infect Dis. 2006;12(1):9-14.

3. Uyeki TM. Human infection with highly pathogenic avian influenza A (H5N1) virus: review of clinical issues. Clin Infect Dis. 2009;49(2):279-290.

4. Nicholls H. Pandemic influenza: the inside story. PLoS Biol. 2006;4(2):e50.

5. Gregg MB, Hinman AR, Craven RB. The Russian flu. Its history and implications for this year's influenza season. JAMA. 1978;240(21):2260-2263.

6. Gao R, Cao B, Hu Y, Feng Z, Wang D, Hu W, Chen J, Jie Z, Qiu H, Xu K, Xu X, Lu H, Zhu W, Gao Z, Xiang N, Shen Y, He Z, Gu Y, Zhang Z, Yang Y, Zhao X, Zhou L, Li X, Zou S, Zhang Y, Yang L, Guo J, Dong J, Li Q, Dong L, Zhu Y, Bai T, Wang S, Hao P, Yang W, Han J, Yu H, Li D, Gao GF, Wu G, Wang Y, Yuan Z, Shu Y. Human infection with a novel avian-origin influenza A (H7N9) virus. N Engl J Med. 2013;368(20):1888-1897.

7. Wang H, Feng Z, Shu Y, Yu H, Zhou L, Zu R, Huai Y, Dong J, Bao C, Wen L, Yang P, Zhao W, Dong L, Zhou M, Liao Q, Yang H, Wang M, Lu X, Shi Z, Wang W, Gu L, Zhu F, Li Q, Yin W, Yang W, Li D, Uyeki TM, Wang Y. Probable limited person-to-person transmission of highly pathogenic avian influenza $A$ (H5N1) virus in China. Lancet. 2008;371(9622):1427-1434.

8. Doerr HW, Varwig D, Allwinn R, Cinatl J. Will the next human influenza pandemic be caused by the virus of the avian flu A/H5N1? Arguments pro and counter. Med Microbiol Immunol. 2006;195(2):4547.

9. De Clercq E, Neyts J. Avian influenza A (H5N1) infection: targets and strategies for chemotherapeutic intervention. Trends Pharmacol Sci. 2007;28(6):280-285.

10. Russell CJ, Webster RG. The genesis of a pandemic influenza virus. Cell. 2005;123(3):368-371.

11. Subbarao K, Murphy BR, Fauci AS. Development of effective vaccines against pandemic influenza. Immunity. 2006;24(1):5-9.

12. Zhang X, Qi X, Zhang Q, Zeng X, Shi Z, Jin Q, Zhan F, Xu Y, Liu Z, Feng Z, Jiao Y. Human 4F5 singlechain Fv antibody recognizing a conserved HA1 epitope has broad neutralizing potency against 
H5N1 influenza A viruses of different clades. Antiviral Res. 2013;99(2):91-99.

13. Baltimore D. Gene therapy. Intracellular immunization. Nature. 1988;335(6189):395-396.

14. Zhang T, Wang TC, Zhao PS, Liang M, Gao YW, Yang ST, Qin C, Wang CY, Xia XZ. Antisense oligonucleotides targeting the RNA binding region of the NP gene inhibit replication of highly pathogenic avian influenza virus H5N1. Int Immunopharmacol. 2011;11(12):2057-2061.

15. Nawtaisong P, Keith J, Fraser T, Balaraman V, Kolokoltsov A, Davey RA, Higgs S, Mohammed A, Rongsriyam Y, Komalamisra N, Fraser MJ, Jr. Effective suppression of Dengue fever virus in mosquito cell cultures using retroviral transduction of hammerhead ribozymes targeting the viral genome. Virol J. 2009;6:73.

16. Zhou $\mathrm{K}, \mathrm{He} \mathrm{H}, \mathrm{Wu} \mathrm{Y}$, Duan M. RNA interference of avian influenza virus H5N1 by inhibiting viral mRNA with siRNA expression plasmids. J Biotechnol. 2008;135(2):140-144.

17. Marasco WA. Intrabodies: turning the humoral immune system outside in for intracellular immunization. Gene Ther. 1997;4(1):11-15.

18. Hu AY, Weng TC, Tseng YF, Chen YS, Wu CH, Hsiao S, Chou AH, Chao HJ, Gu A, Wu SC, Chong P, Lee MS. Microcarrier-based MDCK cell culture system for the production of influenza H5N1 vaccines. Vaccine. 2008;26(45):5736-5740.

19. Sui J, Hwang WC, Perez S, Wei G, Aird D, Chen LM, Santelli E, Stec B, Cadwell G, Ali M, Wan H, Murakami A, Yammanuru A, Han T, Cox NJ, Bankston LA, Donis RO, Liddington RC, Marasco WA. Structural and functional bases for broad-spectrum neutralization of avian and human influenza $A$ viruses. Nat Struct Mol Biol. 2009;16(3):265-273.

20. Oh HL, Akerstrom S, Shen S, Bereczky S, Karlberg H, Klingstrom J, Lal SK, Mirazimi A, Tan YJ. An antibody against a novel and conserved epitope in the hemagglutinin 1 subunit neutralizes numerous H5N1 influenza viruses. J Virol. 2010;84(16):8275-8286.

21. Ekiert DC, Bhabha G, Elsliger MA, Friesen RH, Jongeneelen M, Throsby M, Goudsmit J, Wilson IA. Antibody recognition of a highly conserved influenza virus epitope. Science. 2009;324(5924):246251.

22. Sakabe S, Iwatsuki-Horimoto K, Horimoto T, Nidom CA, Le M, Takano R, Kubota-Koketsu R, Okuno Y, Ozawa M, Kawaoka Y. A cross-reactive neutralizing monoclonal antibody protects mice from H5N1 and pandemic (H1N1) 2009 virus infection. Antiviral Res. 2010;88(3):249-255.

23. Richard S. Agnes MH, and James P. Basilion. Cell penetrating antibodies for intracellular targets: Expanding the antibody-based treatments for cancer. In: Proceedings of the 103rd Annual Meeting of the American Association for Cancer Research. Chicago, IL. Philadelphia (PA); 2012 Mar 31-Apr 4. pp. 4637

24. Kaku Y, Noguchi A, Hotta K, Yamada A, Inoue S. Inhibition of rabies virus propagation in mouse neuroblastoma cells by an intrabody against the viral phosphoprotein. Antiviral Res. 2011;91(1):6471.

25. Goncalves J, Silva F, Freitas-Vieira A, Santa-Marta M, Malho R, Yang X, Gabuzda D, Barbas C, 3rd. Functional neutralization of HIV-1 Vif protein by intracellular immunization inhibits reverse 
transcription and viral replication. J Biol Chem. 2002;277(35):32036-32045.

26. Xun Y, Pan Q, Tang Z, Chen X, Yu Y, Xi M, Zang G. Intracellular-delivery of a single-chain antibody against hepatitis $B$ core protein via cell-penetrating peptide inhibits hepatitis $B$ virus replication in vitro. Int J Mol Med. 2013;31(2):369-376.

27. Karthe J, Tessmann K, Li J, Machida R, Daleman M, Haussinger D, Heintges T. Specific targeting of hepatitis $\mathrm{C}$ virus core protein by an intracellular single-chain antibody of human origin. Hepatology. 2008;48(3):702-712.

28. Vascotto F, Campagna M, Visintin M, Cattaneo A, Burrone OR. Effects of intrabodies specific for rotavirus NSP5 during the virus replicative cycle. J Gen Virol. 2004;85(Pt 11):3285-3290.

29. Corte-Real S, Collins C, Aires da Silva F, Simas JP, Barbas CF, 3rd, Chang Y, Moore P, Goncalves J. Intrabodies targeting the Kaposi sarcoma-associated herpesvirus latency antigen inhibit viral persistence in lymphoma cells. Blood. 2005;106(12):3797-3802.

30. Ashour J, Schmidt Fl, Hanke L, Cragnolini J, Cavallari M, Altenburg A, Brewer R, Ingram J, Shoemaker C, Ploegh HL. Intracellular expression of camelid single-domain antibodies specific for influenza virus nucleoprotein uncovers distinct features of its nuclear localization. J Virol. 2015;89(5):27922800.

31. Niwa H, Yamamura K, Miyazaki J. Efficient selection for high-expression transfectants with a novel eukaryotic vector. Gene. 1991;108(2):193-199.

32. Brondyk B. pCl and pSI Mammalian Expression Vectors. Promega Notes 1994;49: 7-11.

33. Rader C, Popkov M, Neves JA, Barbas CF, 3rd. Integrin alpha(v)beta3 targeted therapy for Kaposi's sarcoma with an in vitro evolved antibody. FASEB J. 2002;16(14):2000-2002.

34. Reed LJ, Muench, H.A. A simple method of estimating fifty percent endpoints. . Am J Hyg. 1938; 27 : 493-497.

35. Krah DL. A simplified multiwell plate assay for the measurement of hepatitis A virus infectivity. Biologicals. 1991;19(3):223-227.

\section{Figures}


A

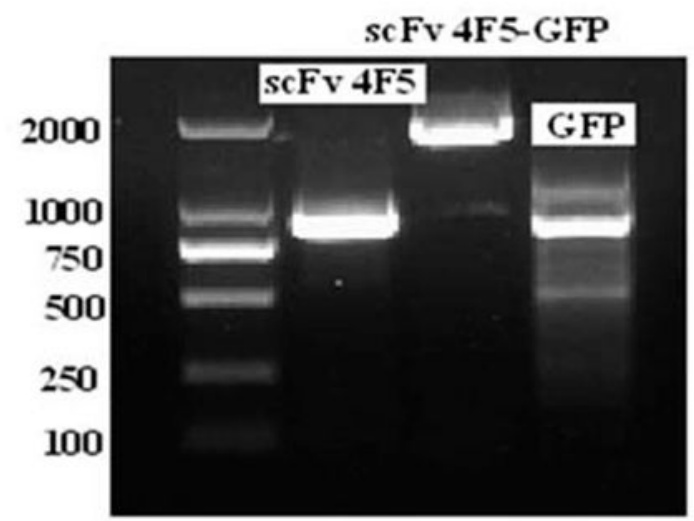

B

\section{Untransfected}
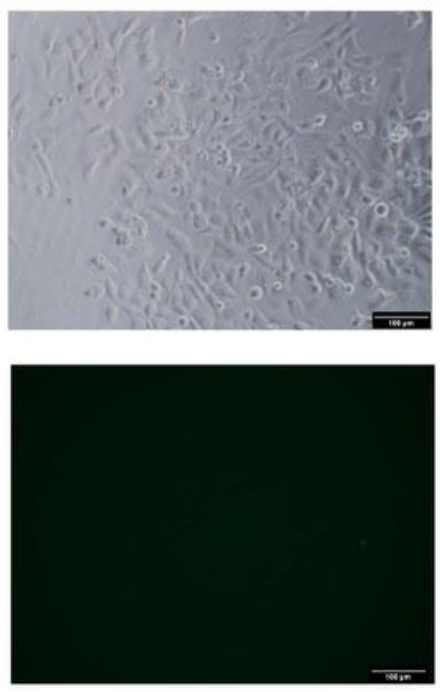

C

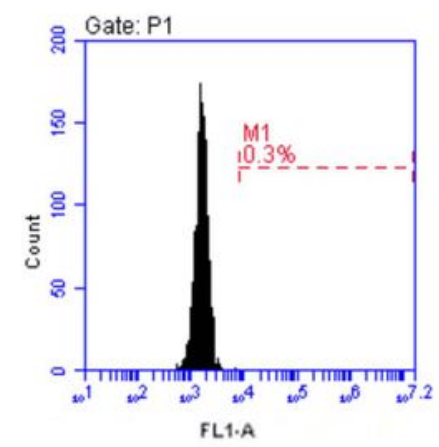

1: 1
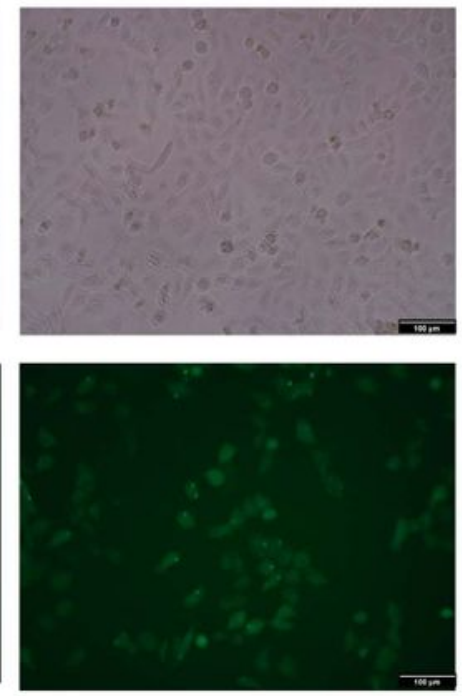

D

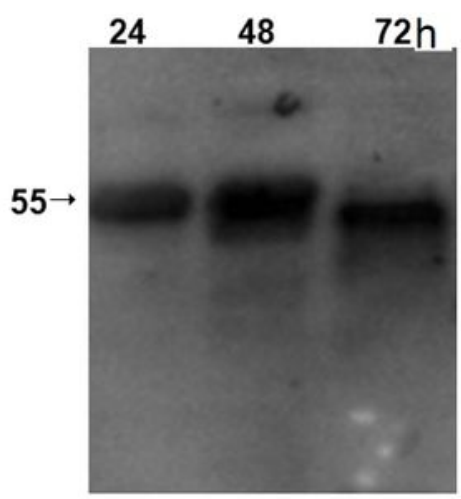

$1: 2$
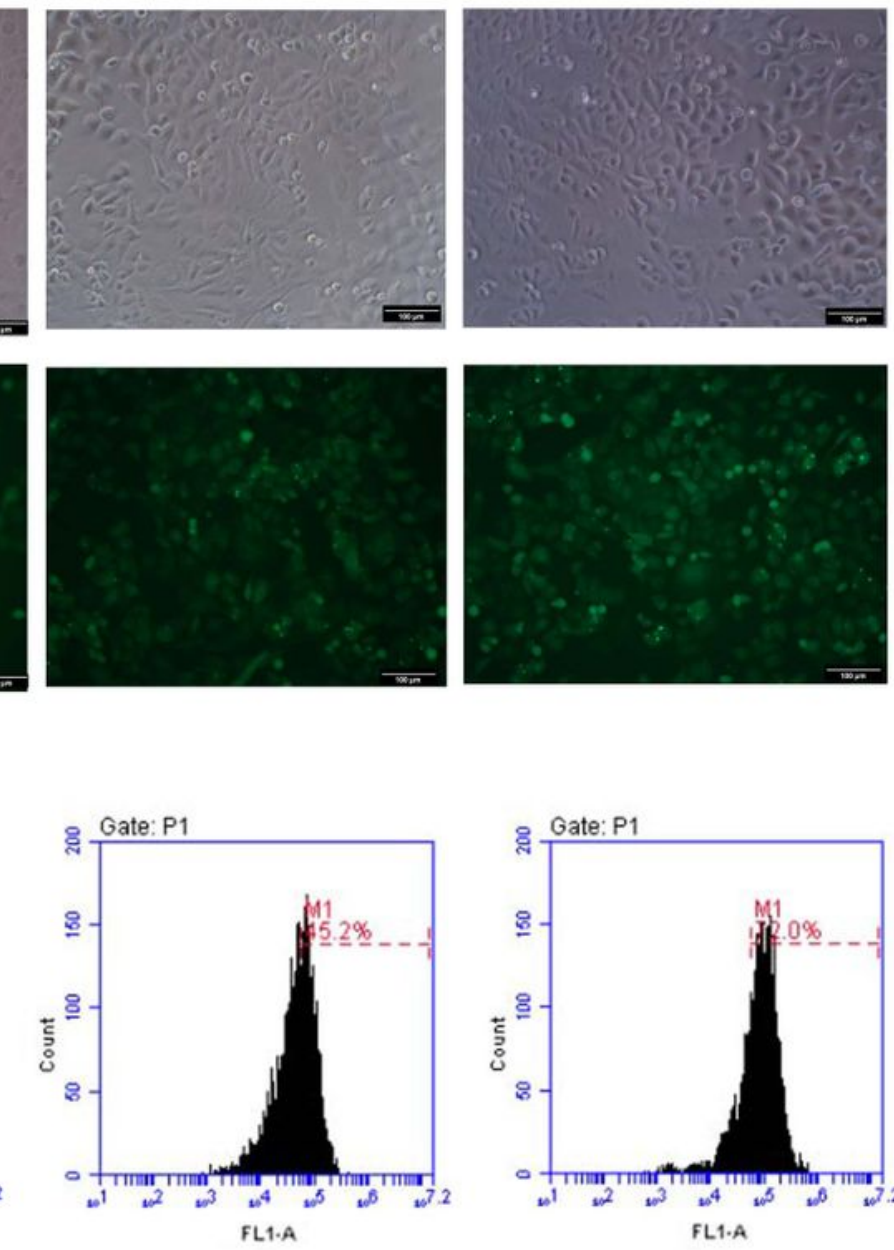

$1: 3$
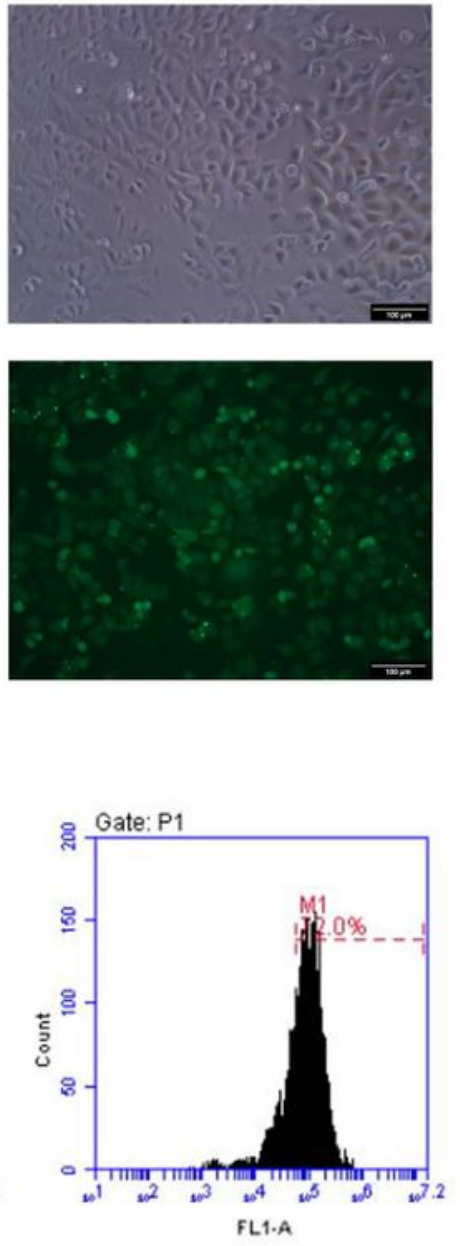

\section{Figure 1}

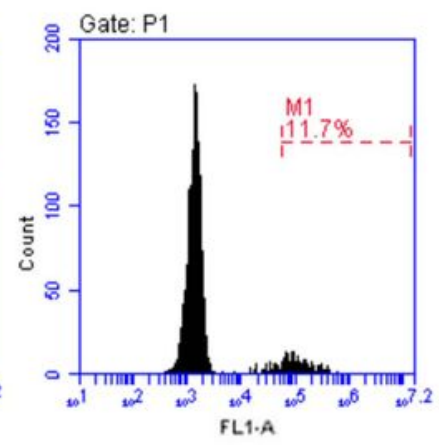

The eukaryotic expression vector pCAG-scFv4F5-GFP was constructed and then transfected into A549 cells. The recombinant vector PCAG-scFv4F5-GFP was amplified by PCR with vector primer, and the PCR products showed that scFv4F5 with the tag sequence was $~ 850$ bp, pCAG-GFP had an $~ 750$ bp EGFP band and pCAG-scFv4F5-GFP had an $\sim 1600$ bp band (A). A549 cells were plated in 6-well plates at a density of $5 \times 105$ cells/well in $2 \mathrm{~mL}$ and grown overnight. Cells were transfected with $3 \mu \mathrm{g} \mathrm{pCAG-scFv4F5-}$ 
GFP vector plus different ratios of Lipofectamine ${ }^{T M} 2000(1: 1,1: 2,1: 3)$. GFP green fluorescence was detected and fluorescence intensity of cells transfected with 1:3 of pCAGsc-Fv4F5-GFP:Lipofectamine ${ }^{\mathrm{TM}}$ was obviously higher than that of others at the same time (B). GFP also detected by flow cytometry at 48 hours was up to $\sim 72 \%$ at the ratio of $1: 3$, and it was only $11.7 \%$ and $45.2 \%$ at $1: 1$ and $1: 2$ (C). Cells transfected at 1:3 pCAG-ScFv4F5-GFP:Lipofectamine ${ }^{\text {TM }} 2000$ were collected and lysed in RIPA buffer at 24, 48 , and 72 hours. The supernatants of the lysed cells were analysed by western blot for expression of scFv4F5 antibody. A $55 \mathrm{kD}$ fragment, which is the size of the antibody, was detected for all treated cells, and the highest production occurred at 48 hours (D).

A

Untransfected
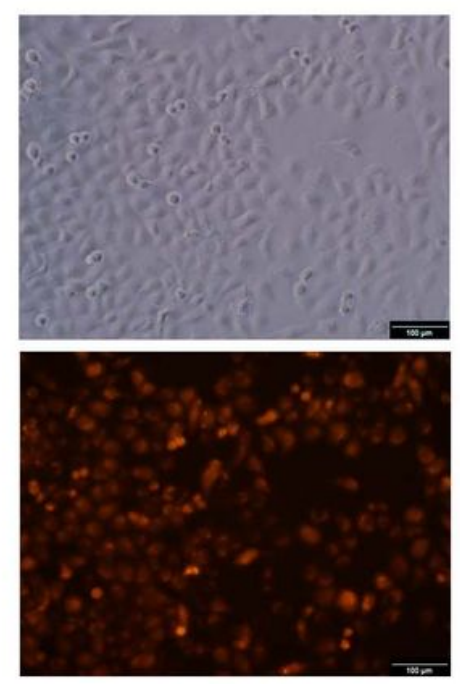

B

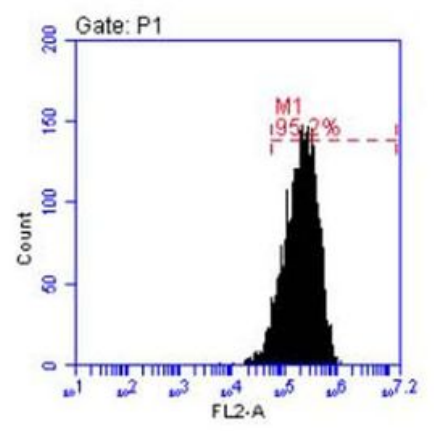

$1 \mu \mathrm{g}$
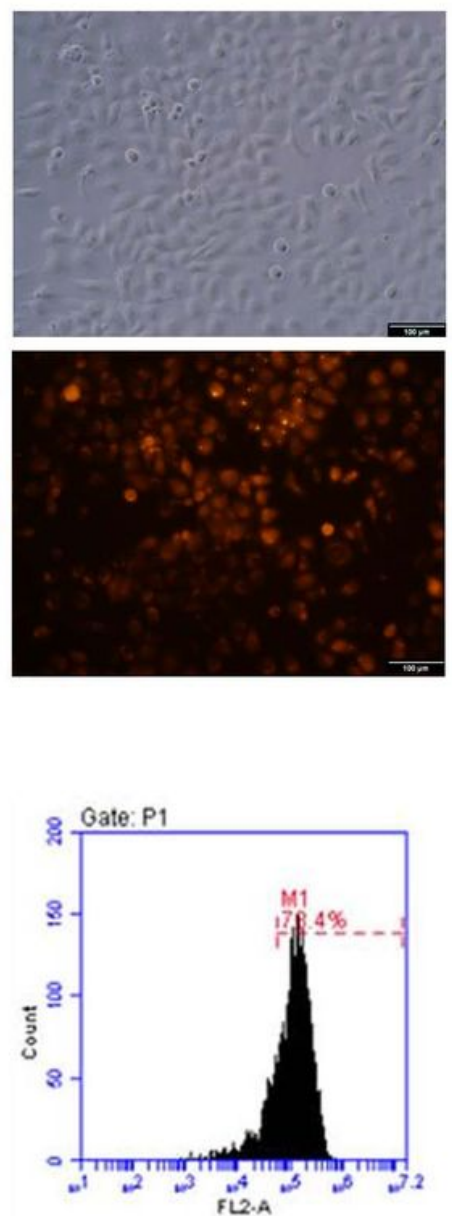

$3 \mu \mathrm{g}$
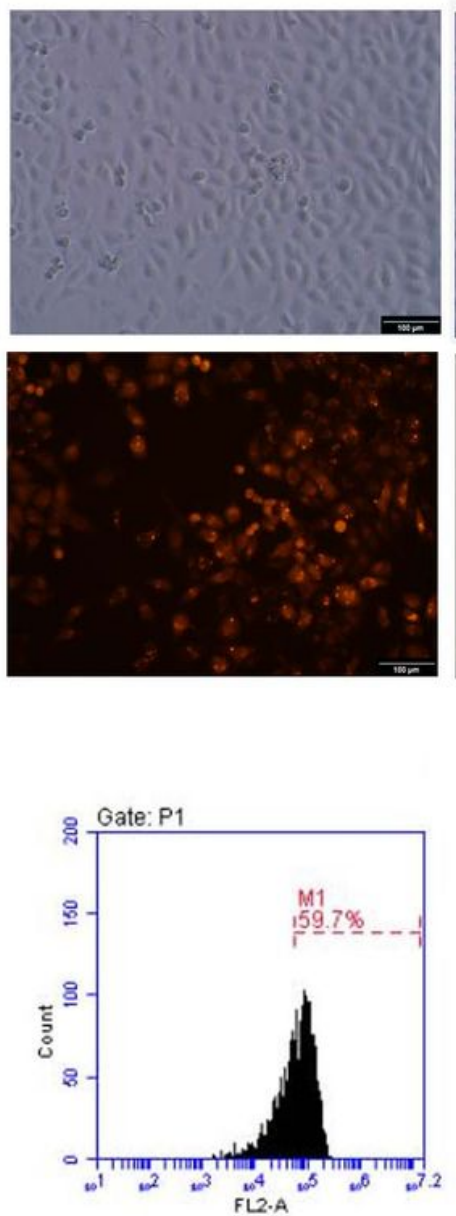

$5 \mu \mathrm{g}$
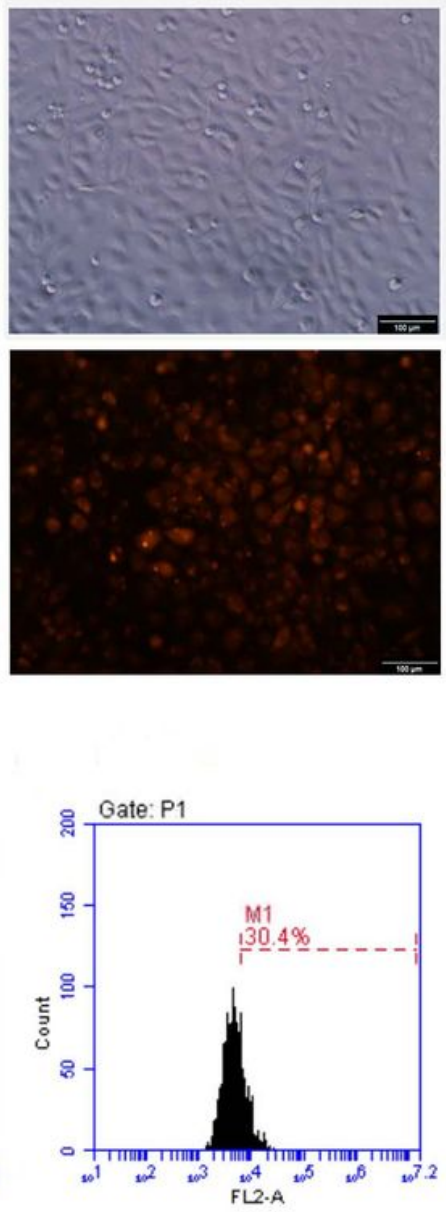

\section{Figure 2}

The expressed intracellular antibody can inhibit H5N1 virus propagation in A549 cells. pCAG-scFv4F5GFP was transfected into A549 cells as above. After 24 hours, the cells were infected with H5N1 virus. The inhibition of $\mathrm{H} 5 \mathrm{~N} 1$ virus propagation by the intrabody was measured as relative virus quantity by flow cytometry at 48 hours after infection. The treated cells were fixed with $4 \%$ paraformaldehyde and permeabilized with $0.1 \%$ Triton X-100 and then consecutively incubated with mouse anti-influenza $A$ virus NP antibody and R-PE-conjugated goat anti-mouse IgG. The cells were observed by using a Carl Zeiss immunofluorescence microscope, and virus quantity was analysed using a BD Biosciences FACSAria II 
flow cytometer. Virus quantity decreased with increasing dose of pCAG-scFv4F5-GFP transfected from 1 to $5 \mu \mathrm{g}(\mathrm{A})$. The percentage of H5N1 virus-positive cells ranged from $95.2 \%$ to $30.4 \%$ (B).

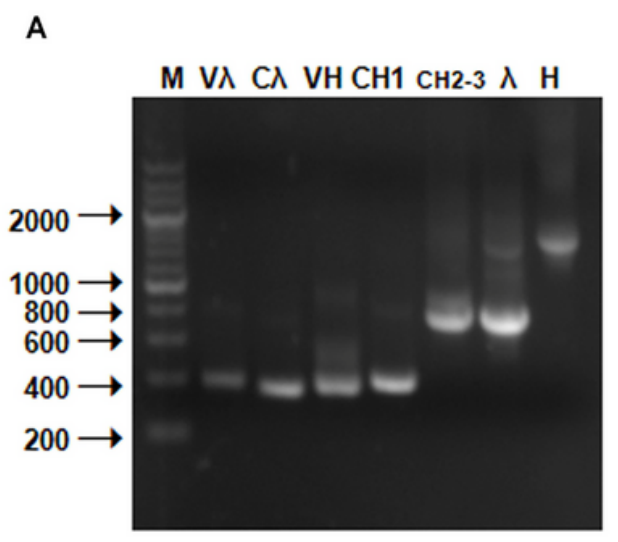

B

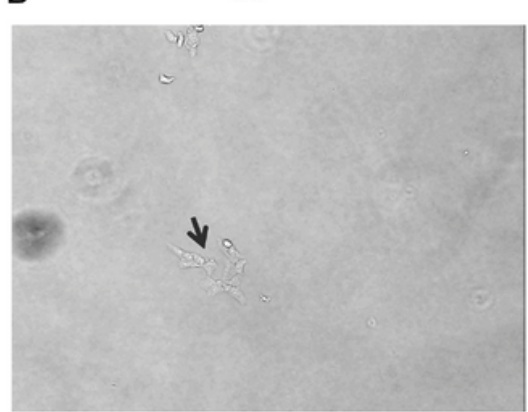

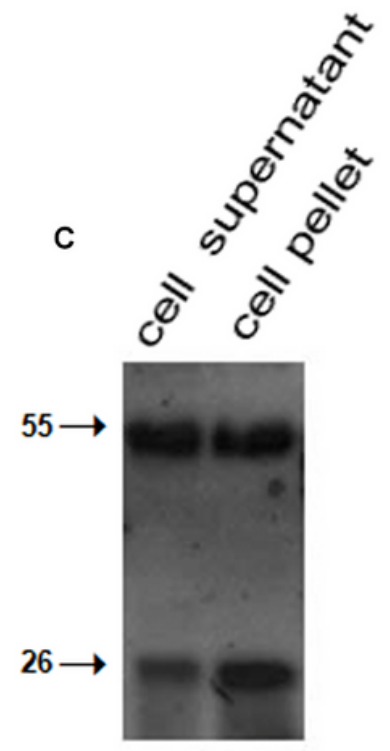

5d

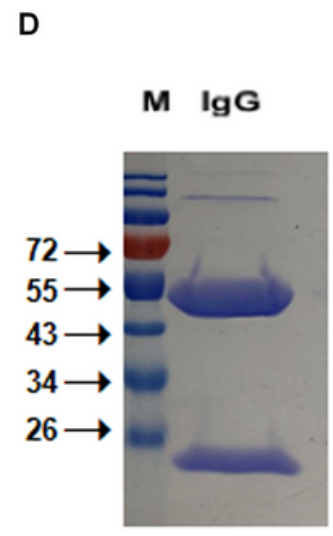

10d

\section{Figure 3}

Full-length human anti-H5N1 virus IgG1 antibody-expressing vectors were constructed and then stably transfected into CHO-DG44 cells. The sizes of genes $\mathrm{V} \lambda, \mathrm{VH}, \mathrm{C} \lambda, \mathrm{CH} 1$ were all $\sim 350 \mathrm{bp}, \mathrm{VH} 2-3$ and $\lambda$ were $\sim 750$ bp, H was $\sim 1500$ bp, as tested by PCR (A). Transfected cells were selected with G418 added 2 days later, and obvious cell colonies were seen at 5 and 10 days (B). The expression of IgG1 was tested by western blotting and antibody $\mathrm{H}$ and $\lambda$ were both expressed in cells and supernatants. The size of $\lambda$ was $25 \mathrm{kD}$, and $\mathrm{H}$ was $55 \mathrm{kD}$ (C). The purified IgG1 was identified by SDS-PAGE, and the size was correct. The purity of the purified IgG1 reached $95 \%$ as analysed by ImageJ software, with the mean grey value of the protein band areas methods (D). 
A
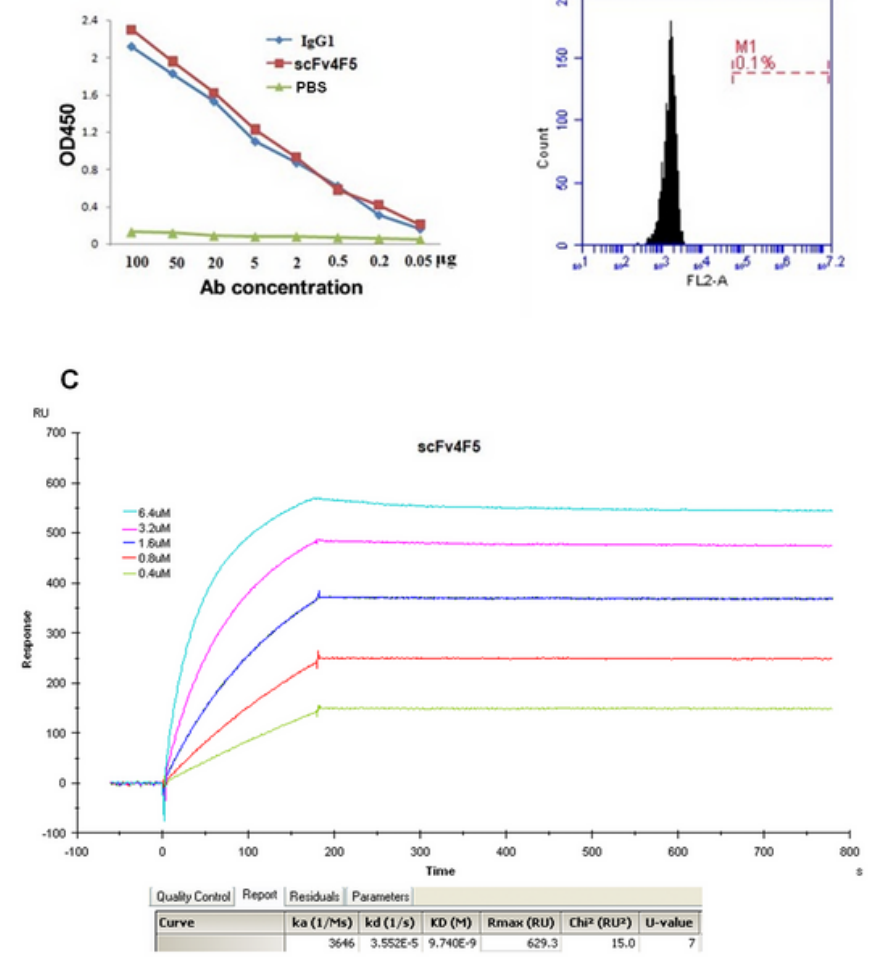

D
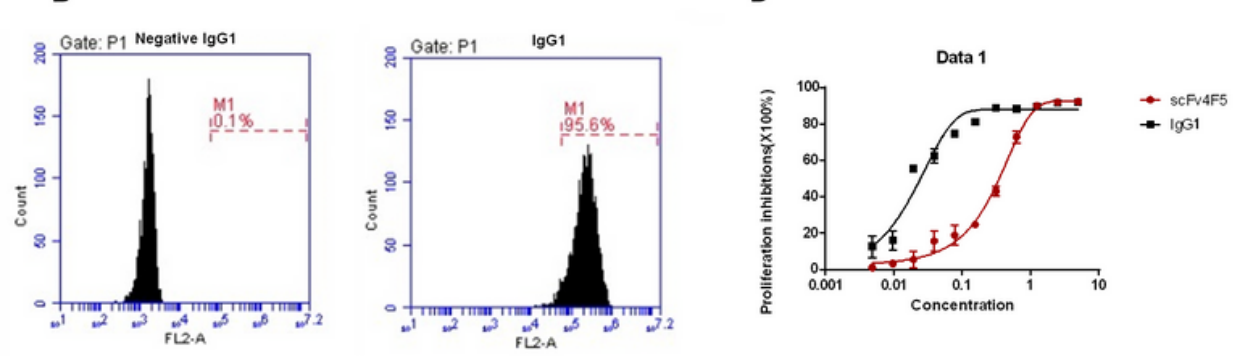

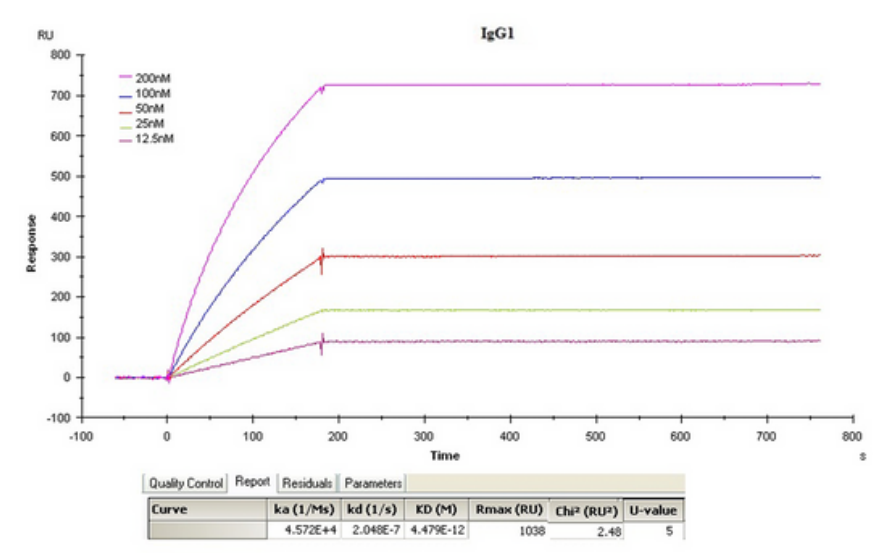

Figure 4

The purified full-length human IgG1 antibody has high specificity, sensitivity and affinity against H5N1 virus ELISA showed that the OD450 of IgG1 and scFv4F5 were almost the same at the same concentrations against the HA1 protein (A). The binding reactivity of IgG1 was detected by flow cytometry, and IgG1 and negative commercial human IgG1 antibody were added 48 hours after MDCK cells were infected by A/Jiangsu/1/2007(H5N1) virus. After incubation for 1 hour at $4{ }^{\circ} \mathrm{C}, \mathrm{R}-\mathrm{PE}-$ conjugated AffiniPure F(ab')2 Fragment Goat Anti-Human IgG was added. After incubation in the dark for 30 minutes at $4{ }^{\circ} \mathrm{C}$, the cells were washed 4 times with PBS containing $1 \%$ BSA. Cells were resuspended in $100 \mu \mathrm{l} 4 \%$ paraformaldehyde and analysed by flow cytometry. The results showed that IgG1 could bind $95 \%$ of virus-infected cells, while the negative lgG1 did not bind with the cells (B). Biacore SPR results showed that the affinity constant kD of IgG1 against the virus was $4.479 \times 10-12$, while the kD of scFv4F5 was only $9.740 \times 10-9$ (C). The microneutralization assay was used to detect the IC50 of the antibodies against virus in vitro. The IC50 of IgG1 was $0.01521 \mu \mathrm{g} / \mathrm{ml}$, lower than $0.3451 \mu \mathrm{g} / \mathrm{ml}$ of scFv4F5. The inhibitory effects of antibodies against H5N1 virus proliferation in MDCK cells are shown (D). 
A

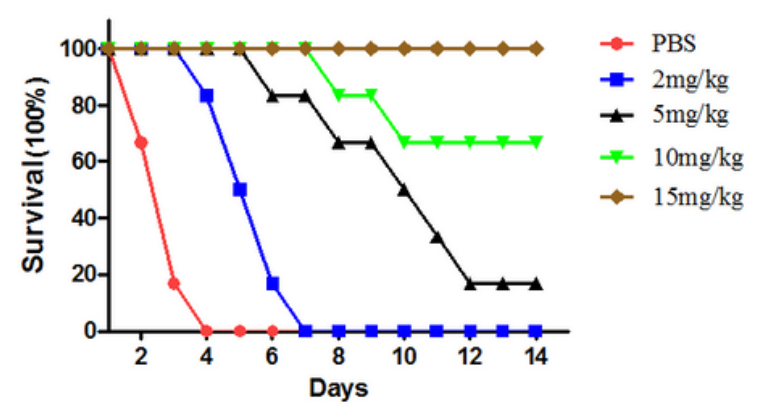

B

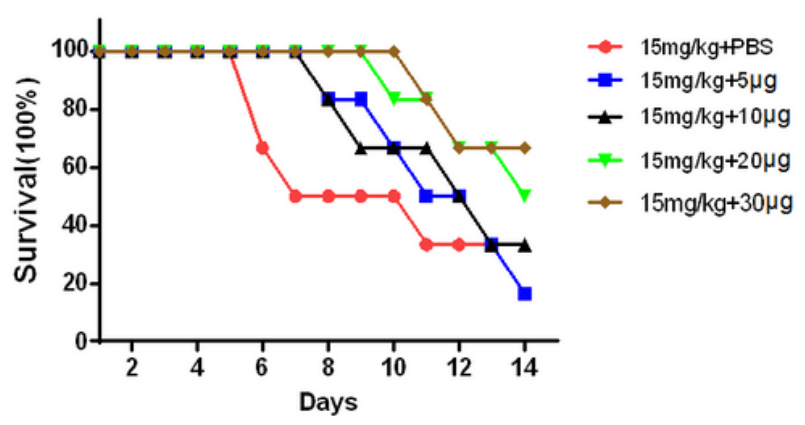

Figure 5

The combination of intracellular and extracellular antibodies has a better protective effect in a mouse model challenged with H5N1 virus. Survival of 100 TCID50 A/Jiangsu/1/2007(H5N1)-challenged mice treated with $\mathrm{IgG} 1$. Mice in the control group and the $2 \mathrm{mg} / \mathrm{kg}$ group all died and the survival rates of the 5 $\mathrm{mg} / \mathrm{kg} 10 \mathrm{mg} / \mathrm{kg}$, and $15 \mathrm{mg} / \mathrm{kg}$ groups were $16.67 \%, 66.67 \%$, and $100 \%$, respectively (A). Survival of mice treated with antibody combinations and challenged with 500 TCID50 A/Jiangsu/1/2007(H5N1). IgG1 was used as $15 \mathrm{mg} / \mathrm{kg}$ invariantly, and when the dose of pCAG-scFv4F5-GFP was $0.5 \mu \mathrm{g}, 10 \mu \mathrm{g}, 20$ $\mu \mathrm{g}$, or $30 \mu \mathrm{g}$, the survival rates were $16.67 \%, 16.67 \%, 33.33 \%, 50.00 \%$, or $66.67 \%$, respectively. (B).

A

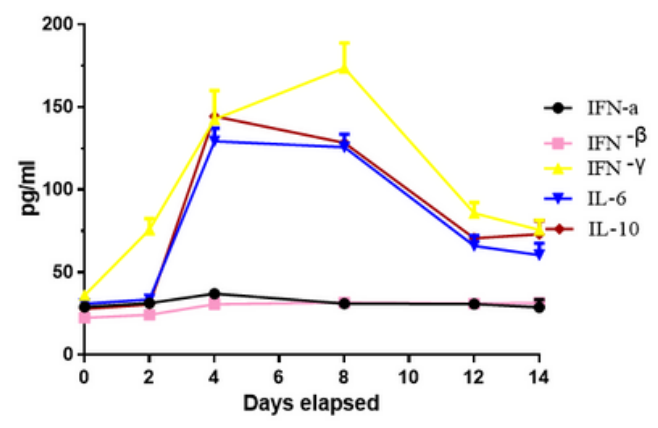

C

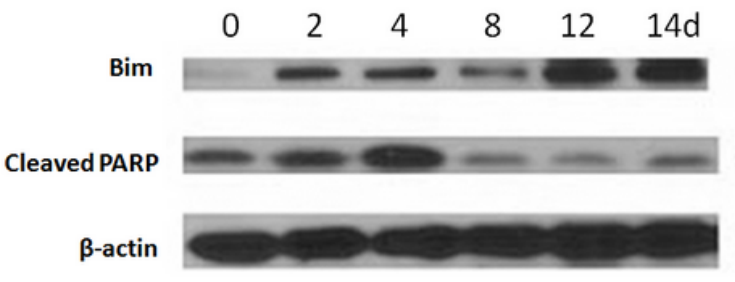

B

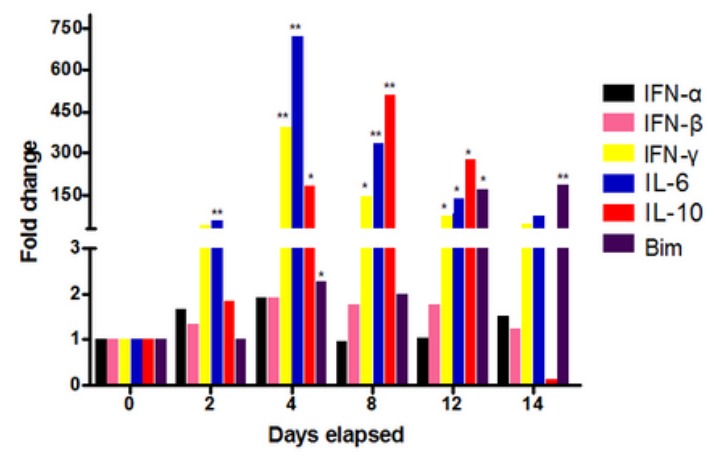

D

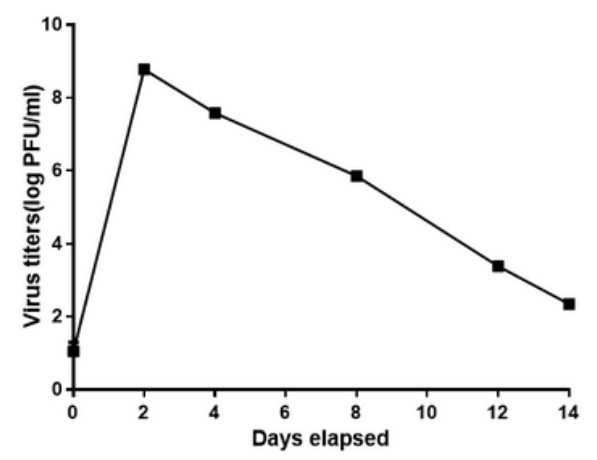




\section{Figure 6}

The increased levels of IFN- $\gamma, \mathrm{CD} 8+\mathrm{T}$ cells, and related cytokines play an important role in the antiviral protection induced by the antibody combination. ELISA was used to detect the levels of cytokines IFN-a, IFN- $\beta$, IFN- $\gamma$, IL-6, and IL-10 (A). Real-time PCR was used to detect the transcriptional level of the cytokines, and the experiment was repeated three times. Data generated in triplicate and fold changes are shown as the mean $\pm S D\left({ }^{*} p<0.05,{ }^{*} p<<0.01\right.$, and $\left.{ }^{* * *} p<0.001\right)$ (B). Western blotting was used to detect the expression of Bim and cleaved PARP (C). Virus titers (PFU/ml) were determined by a plaque-forming assay on MDCK cells. A series of diluted sera were added to MDCK cells and incubated for 24 hours. The medium was then discarded and I\% agarose medium was added. Then, one week later, virus-infected cells were identified by crystal violet staining and virus plaques were counted to calculate the viral titers and analyse viral replication. (D).

\section{Supplementary Files}

This is a list of supplementary files associated with this preprint. Click to download.

- TheARRIVEguidelineschecklist.pdf 